\section{Eye to the rosy lens}

\section{Dorothy Nelkin}

Science and Scientific Researchers in

Modern Society.

By John P. Dickinson.

UNESCO: 1984. Pp.254. FF90.

JoHN Dickinson is an organic chemist who has specialized in biomedical research in clinical laboratories. At present he is an executive in a pharmaceutical firm, with responsibilities for science administration. It is from this diverse perspective that he writes about the role of science and technology in modern society. He begins by expressing distress about what he views as growing public antipathy to science, his end purpose being to demonstrate that in its methods and ethics, as well as its specific contributions, science is an important and positive agent of progress.

Dickinson describes the distinctive features of scientific research, distinguishing it from other data-gathering activities. Tracing the scientific method through the formulation of theories and hypotheses, and the testing of hypotheses by experiment, he argues that it is "the leaven of disciplined imagination which imparts to scientific research a special place among other intellectual activities". He also considers the relationship between fundamental and applied research, drawing attention to the symbiotic and synergistic relationship between science and technology, and the importance of this relationship to the social contribution of science.

With this as background, Dickinson turns to the education and socialization of scientists, suggesting how they are prepared to deal critically and creatively with the multi-faceted and often shifting character of problems. He then describes the social environment of research, career and mobilization patterns, job satisfaction and the question of public recognition.

In the book the scientist is examined as both a professional and a citizen. As professionals scientists are faced with several responsibilities that are sometimes in conflict; for example, their responsibility to "an invisible college" of peers may sometimes conflict with their responsibility for the possible use or abuse of their work. In looking at the scientist as citizen the focus is upon the researcher's responsibility to society, and Dickinson notes the recent shift from the traditional apolitical stance as scientists have increasingly become engaged in controversial issues.

This book wades into most of the major issues in "science and society", the author himself emerging as a profound optimist. Dickinson sees science and technology as the solution to many problems, ranging from the depletion of non-renewable resources to cancer: science is "the potent fuel of change and progress", to be viewed "not only as promoting intellectual freedom generally, but also as enriching culture in the broadest sense". It is an activity that is basic to the construction of "world equity and peace". Thus he calls for scientists to "exercise greater influence upon political life" at all levels.

It is with this attitude that Dickinson returns to his worries over science as a scapegoat. He sees anti-science sentiments as dangerous, threatening and widespread. Yet, violating his own description of how scientists work, he offers no supporting evidence for the assertion. In fact, the evidence available from surveys, and suggested by both public interest in popular science and the tone of most media coverage, is quite otherwise. Dickinson, however, is not alone in his view. Many scientists tend to translate public criticism of certain technologies such as nuclear power, or concern over specific scientific procedures into wholesale rejection of the entire scientific and technological enterprise. I find this curious. Why do scientists expect to be loved? After all, lawyers, doctors, journalists and businessmen are routinely subject to public criticism. Should scientists be exempt? For some reason, no other profession, except perhaps the clergy, expects to be so revered.

Dickinson has painted a helpful and broadly based picture of the scientific community in its many and undeniably important roles. But it is a picture that is more likely to increase awe and overexpectation than to lessen the gap between science and the public. I wish the author had used his material to create a warmer portrait of scientists, less as saviours than as real people engaged, as so many others, in a useful and necessary human enterprise.

Dorothy Nelkin is a Professor in the Cornell University Program on Science, Technology and Society and the Department of Sociology.

\section{Biology by numbers}

\section{George F. Oster}

Modeling Dynamic Phenomena in

Molecular and Cellular Biology.

By Lee A. Segel.

Cambridge University Press: 1984. Pp. 300. Hbk £25, \$49.50; pbk £8.95, \$12.95.

Professor Segel heads the Applied Mathematics Department at the Weizmann Institute, and is one of the leading figures in that shady profession known as biomathematics. This book emerged from lecture notes for a course in mathematical modelling which he has given for several years. Some biologists may still wonder at the demand for such a course. Aside from the "physics envy" that Joel Cohen claims is the curse of biologists, isn't biology still an essentially empirical science? Aren't courses in mathematical biology merely pandering to idle physicists' and mathematicians' lust for 'relevance'? Well, perhaps, but I feel that perusal of this book by any but the most recalcitrant empiricist may thaw that viewpoint.

Professor Segel has striven hard - and succeeded quite well - to select topics of genuine biological interest, and to present their mathematical underpinnings in as clear and understandable a way as one will find anywhere. After all, what is mathematics but a set of rules for logical thinking? And what biologist would shrink from logic? But of course, the issue is not that simple. Biology is, after all, a largely inductive enterprise, and many eons away from the physicists' clean mathematical formulations. The real test of theory comes when the biologist asks: what does mathematics tell me that I didn't know already? Or, what experiments could it suggest that I wouldn't have thought of myself? To the former question a theorist might reply that talk is cheap. It is not sufficient merely to say that something is so: that such and such a conclusion follows from this assumption and that. Only a calculation based on a clearly formulated model can entitle one to draw firm conclusions. Nonsense, replies the biologist. More things are true than you can prove by theorems. And so the argument goes. Finally, I suppose, it is a matter of taste whether one finds mathematical models enlightening or confusing. Despite Darwin's envy of the mathematician's "extra sense", his theory did not suffer much for lack of it.

Professor Segel seems to have had this debate in mind, for he takes care to discuss just what the role of mathematics is in each of the topics he covers. Moreover, he eschews - wisely, I feel - the practice of "general theorizing". He bases each chapter on a particular empirical problem, and builds models which address the issues the experiments raise. The level of mathematics progresses from very elementary in the early chapters to quite advanced in the later ones. However, mathematically untrained readers may never detect the altitude, for Professor Segel has the gift of making advanced notions appear simple. The book is crowned by a collection of appendices which provide sufficient background mathematics that most readers will not have to consult outside sources.

Overall, Professor Segel has done an admirable job of presenting a broad range of mathematical models and techniques at a level suitable for upper division students in the life sciences. For anyone with the slightest interest in modelling biological situations, there can hardly be a better elementary text.

George F. Oster is Professor of Biophysics, Entomology and Zoology at the University of California, Berkeley. 